Estudios Constitucionales, Año 8, No 1, 2010, pp. 137 - 168.

ISSN 0718-0195

Centro de Estudios Constitucionales de Chile Universidad de Talca

"Argumentos contra la tortura y los tratos crueles, inhumanos y degradantes"

Fernando M. Machado Pelloni

\title{
ARGUMENTOS CONTRA LA TORTURA Y LOS TRATOS CRUELES, INHUMANOS Y DEGRADANTES ${ }^{1}$
}

\author{
Arguments against of Torture And other Cruel, \\ INHUMAN OR DEGRADING TREATMENT
}

\author{
Fernando M. Machado Pelloni² \\ Profesor de la Universidad de Buenos Aires \\ fmachadopelloni@hotmail.com
}

RESUMEN: Esta investigación persigue trasladar situaciones tratadas por la jurisprudencia de la Corte Europea de Derechos Humanos en lo que hace a la prohibición de tortura, tratos crueles, inhumanos y degradantes, al ámbito regional del MERCOSUR, especialmente desde Argentina y Brasil. En tal sentido, luego de ubicar disposiciones internacionales y puntos básicos en el tema, se persiguen respuestas sobre tres focos de atención: la teoría de la pena, la ejecución penitenciaria y la investigación. Desde aqui se introducen los análisis más recientes y más permeables contra una regla que se juzga absoluta y se los critica. La esfera politica y jurídica, como las interna y externa son estudiadas en el objetivo de alcanzar en el presente y en el futuro, igual rechazo que en el pasado.

ABSTRACT: The investigation follows to transfer treated situations by European Court of Human Rights jurisprudence over phohibition of torture, cruel and degrading treatments, to the regional scope of the MERCOSUR, specially from Argentina and Brazil. In such sense, after to locate international public law rules and basic points in the subject, answers are persecuted on three centers of atention: theory of punishment, the penitentiary execution and the investigation. From the most recent and more permeable analyses against a rule that is judged absolute and the criticism are introduced here. The political and legal, internal and external spheres are studied in the objetive to reach in the present and the future, equal rejection that in the past.

PALABRAS CLAVE: Prohibición de tortura, tratos crueles, inhumanos y degradantes. Pena, ejecución penal e investigación bajo la regla. Corte Europea de Derechos Humanos.

KEY WORDS: Prohibition of torture, cruel and degrading treatments. Punishment, penitentiary execution and investigation under the rule. European Court of Human Rights.

\footnotetext{
${ }^{1}$ Artículo recibido el 15 de noviembre de 2009 y aprobado el 31 de marzo de 2010.

${ }^{2}$ Docente de la UBA. Doctorando con Tesis Presentada. Profesor visitante de la Università degli Studi di Roma "La Sapienza" y del UniRitter Dos Reis, Porto Alegre-Rio Grando do Sul. Ex investigador Antica Università degli Studi di Camerino y Università degli Studi di Urbino. Ex Becario de Europa-Viadrina Universität, Frankfurt-Oder. Miembro Asociado de la Asociación Argentina de Derecho Constitucional y de Profesores de Derecho Penal. Miembro del Circulo Doxa de Buenos Aires www.circulodoxa.org Defensor Público Oficial Adjunto de la Defensoría General de la Nación Argentina por concurso público y actual candidato a la Fiscalía Federal No 2 de San Isidro, Buenos Aires, también por concurso público.
} 
A los sospechosos y detenidos que encuentran dificultades para hablar con un abogado defensor. A los jueces que lo hacen posible. A los superiores de éstos también.

The more you explain it, the more I don't understand it.

Mark Twain

\section{ACERCA DE LA ELECCIÓN DEL TEMA.}

A SU VEZ, LA LUZ SOBRE EL CENTRO DEL ANÁLISIS

La actualidad del tema podría, para cualquier desprevenido, ser un obviedad. No por ello justamente. En realidad, por pensar a donde conduce. Obsérvese lo que recientemente sentenciara un historiador en un periódico inglés: "incluso durante las más oscuras horas de la Segunda Guerra Mundial, Gran Bretaña no recurrió a prácticas de barbarie”. Que agencias de un país tan pequeño como enormemente civilizado no informen sobre lo que sucede con sospechosos en puntos distribuidos a lo largo del globo, lo cual se sabe, es tan preocupante como lo que se desconoce. Con una agravante: adhiere a los instrumentos y a un sistema de protección reconocido, que prohíbe la tortura. No persigo aquí ver si acaso es cierto que hoy día los Estados democráticos se acercan a -o son- lo que otrora combatían. Sin embargo, destacaré que bajo la prudencia propia de andar en un terreno pantanoso, se puede arribar a que cientos de disposiciones protectoras de la libertad puedan ser, por mil modos, a propósito, por indiferencia o por directa ignorancia, apenas tinta en papel.

Ya no podría parecer, a esta altura del ingreso en la nueva centuria o más, del ya superado milenio en todo el sentido de la expresión, que volver sobre la tortura sea innecesario: las buenas razones que movilizaron a su exclusión en el ámbito de la teoría de la pena, también de su ejecución o del proceso penal, se supone al parecer, no eran lo bastante consistentes como para bloquear el volver, justamente, hacia aquello que ha sido dejado atrás. Para decirlo con claridad, explorar su problematización, en alguna medida, habría concluido con ser un apéndice -importante desde luego- de la historia del derecho penal o del derecho internacional de los derechos humanos. Esto debía ser todo. Sin embargo, sería un error, de proporciones por cierto. Con todo advierto: la pesquisa ha encontrado distancias entre lo antiguo y lo nuevo. Es decir, hay modificaciones, adaptaciones, de donde se alcanza un punto que, en cierto modo, es el avance del retroceso.

Tener por superada la edad que aplicaba la tortura, la definía y la predicaba no es más que una ilusión. No hay que comenzar forzosamente un viaje hacia

\footnotetext{
${ }^{3}$ Cfr. Burleigh, Michael, "Why we must have an inquiry into ministers'collusion in torture", en Daily
} Mail, London-UK, 5/8/09, p. 14. 
atrás para dar con su hallazgo. En cualquier caso, sin dejar de recordar lo que fue del pasado, será núcleo de atención dar un giro sobre algunas decisiones contemporáneas, con capacidad para proyectarse -o eso debe esperarse-, con la mirada puesta en el horizonte, en lo que hace al futuro. Esto no conmueve aquellas buenas razones contra la tortura. No creo -y me ocuparé después- que se las superara. Al contrario, el paisaje del conglomerado de hechos y fundamentos que se han buscado en pos de alguna señal aprobatoria de un relativismo contra ellas, en mi opinión, las reafirman.

Lo que me propongo es estudiar algunas decisiones de la Corte Europea de Derechos Humanos. A partir de ellas, podré trazar una clasificación capaz de operar como contenedor de los atajos que pretenden hacernos olvidar de la difícil senda a transitar por Estados con obligaciones con aquellos y que, en consecuencia, les prohíbe total y absolutamente aplicar por acción o consentir por omisión la tortura, lo que a su tiempo construye nuevos tramos para la proscripción de los tratos crueles, inhumanos o degradantes.

\section{INGRESO: TORTURA Y TRATOS CRUELES,}

\section{INHUMANOS O DEGRADANTES Y SU PROHIBICIÓN COMO REGLA}

En lo que hace a una definida prohibición de la tortura, como del trato cruel, inhumano o degradante el trato normativo se ha enmarcado muy especialmente a partir del derecho internacional de los derechos humanos ${ }^{4}$. La Convención Europea dispone específicamente al respecto que nadie será sometido en este puntos. Por igual, también el texto del instrumento americano, popularmente conocido como el Pacto de San José de Costa Rica ${ }^{6}$. La única distancia entre ambos es que la regla de libertad negativa, en cuanto a que los Estados no deben proceder así contra las personas y de la cual todos participan, cuenta en el último además con otra

\footnotetext{
${ }^{4}$ DUDH. (París, 10-XII-1948) art. 5: "Nadie será sometido a torturas ni a penas o tratos crueles, inhumanos o degradantes". Con un importante término ausente, la Declaración Americana de los Derechos y Deberes del Hombre (Bogotá, 30-III-1948), art. 26 Derecho a proceso regular: "Toda persona tiene derecho ... a que no se le imponga penas crueles, infamantes o inusitadas".

${ }^{5}$ ECHR. (Roma, 4-XI-1950), art. 3 Prohibition of torture: "No one shall be subjected to torture or to inhuman or degrading treatment or punishment".

${ }^{6} \mathrm{CADH}$. (San José, 22-XI-1969) art. 5 Derecho a la integridad personal: "2. Nadie debe ser sometido a torturas ni a penas o tratos crueles, inhumanos o degradantes. Toda persona privada de libertad será tratada con el respeto debido a la dignidad inherente al ser humano". Ingresó al derecho interno argentino en 1984 por Ley 23.054 y explícitamente hizo cumbre en la jerarquía normativa a través del inc. 22 del art. 75 CN., en 1994. En Brasil, el tratamiento constitucional se recepta en el art. $5^{\circ}$, III y XLIII, con el agregado infraconstitucional de la Ley 9.455 de 1997.
} 
de tipo positiva: aquéllos se suman con el deber de actuar en modo compatible con la dignidad humana ${ }^{7}$.

Otros importantes documentos recogen la proscripción, sean del derecho internacional de los derechos fundamentales y del derecho internacional humanitario también. Así está el caso del Pacto Internacional de los Derechos Civiles y Políticos ${ }^{8}$, como el de la respectiva Convención contra la Tortura'. Hasta existe una en la esfera americana ${ }^{10}$. La traducción es la siguiente: la Convención contra la Tortura pone a los Estados en la obligación de perseguir penalmente su comisión, lo que ya había asumido Argentina, por propia experiencia en lo que a su aplicación tocaba ${ }^{11}$.

En otra esquina, y según apenas recién se anunció están las Convenciones de Ginebra, que intentan controlar el derecho en la guerra, para repasar una idea completamente y fin necesario, aunque prácticamente absurdo en lo que a un conflicto armado en curso se refiere. Ellas, y no sin esfuerzo, asoman consecuentemente cuando aquél llegó a su fin, a la hora de juzgar como se obró en ella. Proceden en conflictos internacionales, como en los que no lo son ${ }^{12}$.

\footnotetext{
${ }^{7}$ Cabe resaltar que no es forzoso -o no debiera serlo bajo la hermenéutica- concluir que toda prohibición sea acompañada de un deber. No obstante, el contraste de blanco sobre negro, en lo que a la actuación de los Estados en esta área se ve teñido por una estela de grises de lo que resulta, entonces, mucho mejor el complemento de obligación de comportamiento.
}

${ }^{8}$ PIDCP. (New York, 16-XII-1966), art. 7: "Nadie será sometido a torturas ni a penas o tratos crueles, inhumanos o degradantes. En particular, nadie será sometido sin su libre consentimiento a experimentos médicos o científicos". Cfr. íd., art. 10: "1. Toda persona privada de libertad será tratada humanamente y con respeto debido a la dignidad inherente al ser humano". Se lo encontró parte del ordenamiento jurídico argentino por Ley 23.313 y trepó -en la máxima valoración- por su mención en el inc. 22 del art. 75 CN., en 1994.

${ }^{9}$ Convención contra la Tortura y otros Tratos o Penas crueles, inhuamanos o degradantes, Naciones Unidas, 10-XII-1984. De este instrumento surgen acciones negativas pero también positivas para los Estados. En la cúspide normológica argentina desde 1994, por su mención expresa en el art. 75 inc. 22 CN., siendo que ingresó por Ley 23.338.

${ }^{10}$ Convención Interamericana para prevenir y sancionar la Tortura, Washington, 10-II-1986. Como en el anterior caso, de aquí parten obligaciones en dos sentidos: de protección y de promoción de la dignidad humana.

${ }^{11}$ La Ley 23.097 de 1984 modificó el CPA. e ingresó los arts. 144 tercero -imposición de tortura, con más agravantes cualificadas por el resultado-, 144 cuarto -omisión (propia o impropia según interpretación) de evitarla o denunciarla- y 144 quinto -omisión de culpabilidad culposa-.

${ }^{12}$ La tortura, como así también los tratos inhumanos, que afectan la dignidad, están situados por lo común en todas las Convenciones de Ginebra, bajo los arts. $3^{\circ}$. Sea la CG I (3.I.a,c) -heridos y enfermos en fuerzas armadas- gestada en evolución revisada desde 1864, como la CG II (3.I.a,c) -expansión de la primero al área marítima- cuya fuente se remonta a 1868, como la CG III (3.I.a,c) -prisioneros de guerra- asomada en borrador desde 1874 y consolidada entre 1918 y 1929, así como la CG IV (3.I.a,c) -de civiles en conflictos armados internacionales-introducida como cuestión del derecho internacional humanitario a partir de 1921, son contundentes en cuanto a su prohibición. La CG I la ubica como grave violación en el art. 50; la CG II 
Finalmente, el Estatuto de Roma, en lo que se dirige a la materia estrictamente internacional penal. ${ }^{13}$ Proceder en contradicción a los mandatos de Ginebra se corresponde con uno de los delitos-tipos atrapados como crímenes de guerra. Efectivamente, a poco de ingresar en el Tratado, se define, para el propósito del instrumento, que uno de los delitos así denominado responde a la tortura o a los tratos inhumanos, incluyendo la experimentación biológica ${ }^{14}$. Esto a su vez se extendió, de modo coherente con la técnica de las Convenciones de Ginebra, a los conflictos que no alcancen el carácter de internacional o sea, entre dos o más Estados ${ }^{15}$.

Una de las razones de este arsenal normativo supranacional y su espejo interior es su significación: lo que subyace en la proscripción es el reconocimiento y la defensa de la dignidad humana y su recepción es una frontera, no en una teoría penal, antes bien en una específica teoría del Estado. Esta tesis ha sido suscrita en modo constante por la Corte Europea de Derechos Humanos, lo cual sobresale desde algunos de sus precedentes más importantes elaborados sobre la cuestión: "El Tribunal reafirma que el Artículo 3 encierra uno de los valores más fundamentales de una sociedad democrática. A pesar de la más difícil de las circunstancias, como ser la lucha contra el terrorismo, la Convención prohíbe en términos absolutos la tortura o un trato inhumano o degradante o un castigo así. Ninguna disposición es dada, en claúsula sustantiva del Tratado y sus Protocolos, para excepciones y no hay derogación desde lo que es posible bajo el Artículo 15"16.

Varias aproximaciones quieren colaborar con una explicación a la tesis. De un lado, utilitarista-eficaz, una política de tortura no restablece la justicia-sea lo que se quiera definir en ella-, antes mal que bien, reactiva lo peor del poder ${ }^{17}$. Tal cosa

hace lo propio en el art. 51; la CG III por su lado se repite en la solución en el art. 130 y, finalmente, la CG IV adopta tal postura en el art. 147. Todos estos dispositivos son considerados una importantísima contribución en la definición de los crímenes de guerra según el derecho internacional público. Cfr. The Geneva Conventions of august 12-1949, (2008, Geneva, Switzerland, International Committee of the Red Cross) p. 6. Por otra parte, los Protocolos Adicionales para víctimas de conflictos internacionales armados y para los no internacionales, también cuentan con especificaciones propias, CGPAI art. 75.2.ii y CGPAII 4.2.a.

${ }^{13}$ Argentina ratificó el Estatuto en enero 16 de 2001, aprobado por la Ley 25.390. Más tarde por la ley 26.200 reprodujo en la adecuación a éste, en la inteligencia del principio de complementariedad de la Corte Penal Internacional, el art. 8 en el art. 10.

${ }^{14}$ Cfr. art. 8.2.a.ii.

${ }^{15}$ Cfr. art. 8.2.c.i.

${ }^{16}$ Cfr. ECHR, Aktas v. Turkey (judgment), ap. 310; app. 24.351/94, rta. 24/04/2003. En tanto, la disposición mencionada es así, Art. 15.2 Derogation in time of emergency: "No derogation from... article 3...". Hay resistencia, sin embargo, a esta versión literal que no deja de ser pro persona, por aplicación de cierta sistematicidad que analizaré ut-infra. Ver Gössel, Karl Heinz (2007), pp. 18 y ss.

${ }^{17}$ Cfr. Foucault, Michel (2008), p. 60. 
va a contramano del Estado democrático. También en un sentido adverso corre el anti-igualitarismo personal en la arena de la validez. Cabe recordar que, no sin un enorme testimonio de sangre, (todos) los que hacemos parte de la humanidad contamos con dignidad, lo que traslada al campo jurídico la inviolabilidad de cada ser humano. Ello condiciona la política del Estado, al menos en la medida en que cualquier plan orientado a un objetivo, debe separar costos de aquella axiología: en efecto, mientras que los primeros como precios pueden sustituirse con iguales títulos, lo que sea superior y no admita el procedimiento es un fin en sí, sin relatividad y es la propia personalidad de todos los seres vivientes ${ }^{18}$. Este último costado es de magnitud estructural: la invalidez se razona por lo que hace de los agentes que ejecutan el acto, como de los que lo padecen. Tal y como se analizara en las huellas del horror de la Segunda Gran Guerra, no queda señal del valor del individuo en la víctima, pero tampoco en el victimario ${ }^{19}$.

Así la prohibición de tortura -extendida a tratos crueles, inhumanos y degradantes- es una regla en la plasticidad de la dignidad o, presentado mejor, la última es así presentada en lo que toca al tratamiento de las personas. Esta reciente afirmación tiene una importancia trascendental en la teoría del derecho y más precisamente en la de la norma jurídica ${ }^{20}$ : la dignitas muchas veces se puede presentar además como principio o valor indisponible ${ }^{21}$, capaz per se de orientar en un único sentido ${ }^{22}$, aunque múltiple o variable en su producto normativo ${ }^{23}$, la dirección de la tarea en el poder estatal ${ }^{24}$.

\footnotetext{
${ }^{18}$ Sobre "Zweck an sich selbst", KANT, Immanuel (1999), pp. 42 y ss.

${ }^{19}$ Acuerdo en sobrevivientes, en cuanto a que ningún grupo era más humano que el otro, AGAMBEN, Giorgio (2005), p. 16.

${ }^{20}$ Es claro que son los preceptos penales los que son en un punto órdenes precisas por excelencia, pero los comandos pueden asumir otras variantes; cfr. HART, H. L. A. (1997), pp. 27 y ss. Sobre la difícil sanción cuando las prescripciones son tan altas en el ordenamiento, BoBBIO, Norberto (1992), pp. 130 y ss. Entiendo que califica la agrupación de unidad del orden jurídico en el establecimiento de instituciones, deberes de aplicación (mejor, obligaciones) y limitaciones; RAz, Joseph (1997), pp. 155 y ss.

${ }^{21}$ Así, por ejemplo art. 1.1 GG. de Alemania Federal: "Die Würde des Menschen ist unantastbar. Sie zu achten und zu schützen ist Verpflichtung aller staatlichen Gewalt".

${ }^{22}$ Cfr. Alexy, Robert (2002), pp. 81 y ss., con la aventura de discusiones que despierta. Así GarCía FigueroA, Alfonso (1998), pp. 327 y ss.

${ }^{23}$ Es la función de un principio constitucional, con aplicación a la política. Cfr. ZAGREBELSKY, Gustavo (1992), pp. 150 y ss. En sentido análogo, con extensión a la interpretación y críticas al consecuencialismo, DwORKIN, Ronald (1985), pp. 72 y ss. Como integridad e interno compromiso del orden jurídico, DwORKIN, Ronald (1986), pp. 178 y ss. Un estudio sobre las soluciones, García FigueroA, Alfonso, (1998), pp. 219 y ss.

${ }^{24}$ Así para el derecho constitucional argentino -como axioma para teoremas-, cerca a una década de su partida, EKMEKDJIÁn, Miguel A. (1993), p. 81.
} 
La regla, en cambio, es (lo bastante) unívoca. Aunque es verdad que puede ser una usina de problemas - políticos y jurídicos- de cara a resolver otros conflictos, no es falso que resulta entonces inaceptable e injustificable en un Estado democrático la tortura, como también los tratos crueles, inhumanos y degradantes. Obsérvese que cuando una proposición constitucional veda un comportamiento en absoluto es ordenatoria-dependiente, sino autoaplicativa-independiente, razón por la que cualquier diagramación constituyente no debe ser -en el territorio de los derechos fundamentales- confundida con un consejo al legislador o a cualquier otro funcionario del poder ${ }^{25}$. En este último caso, no podría ciertamente arrojar un resultado contradictorio: todo debería ser inclusivo del valor, guiado por el principio, coordinándose cualquier normativa, salvo que se la deba de excluir por oposición ${ }^{26}$.

\section{RENDIMIENTO EN LA TEORÍA DE LA PENA, LA EJECUCIÓN,} LA PREVENCIÓN O INVESTIGACIÓN Y LA PRUEBA DEL PROCESO PENAL:

NÚCLEO Y ÓRBITAS DE PROHIBICIÓN

Según la Asamblea General de Naciones Unidas: "A los efectos de la presente Convención, se entenderá por el término 'tortura' todo acto por el cual se inflija intencionadamente a una persona dolores o sufrimientos graves, ya sean físicos o mentales, con el fin de obtener de ella o de un tercero información o una confesión, de castigarla por un acto que haya cometido, o se sospeche que ha cometido, o de intimidar o coaccionar a esa persona o a otras, o por cualquier razón basada en cualquier tipo de discriminación, cuando dichos dolores o padecimientos sean infligidos por un funcionario público u otra persona en el ejercicio de funciones públicas, a instigación suya, o con su consentimiento o aquiescencia. No se considerarán torturas los dolores o padecimientos que sean consecuencia únicamente de sanciones legítimas, o que sean inherentes o incidentales a éstas" ${ }^{27}$; y, por otro lado,

\footnotetext{
${ }^{25}$ Cualquier conflicto entre derecho internacional de los derechos humanos y derecho constitucional debe resolverse, llegado el caso, con recurso de interpretación judicial, con toda la libertad y la limitación a ella que existe. Yo explicaría como un error, entonces, que se sostenga que la disposición del art. $5^{\circ}$ (XLIII) de la Constitución de 1988 de Brasil sea "programática" en lo que a la tortura se refiere, si en especial de allí no resta espacio semántico: la intervención infra-constitucional debe ser seguida como un ajuste de detalles, en lo que hace a la naturaleza de pena y sus márgenes, no en cuanto a definición. En contra, MoraEs, Alexandre De (2007), p. 106. Ver argumentos en cuanto a concretización, Piovesan, Flávia-STanziola Vieira, Renato (2009), pp. 339 y ss., 354.

${ }^{26}$ Más allá del art. 1 GG, el 104.1 es fulminante: Festgehaltene Personen dürfen weder seelisch noch köperlich miBhandelt werden". Sin embargo, hay quienes desconocen tal contundencia con base a situaciones análogas, fácticas o jurídicas. Cfr. Gössel, Karl Heinz, pp. 30 y ss. Podría sumarse el art. 3 CI como otro ejemplo.

${ }^{27}$ Convención contra la Tortura y otros Tratos Crueles, Inhumanos o Degradantes, Naciones Unidas, diciembre 10 de 1984, art. 1.1.
} 
como corolario teleológico del instrumento, se suscribió que "el presente artículo se entenderá sin perjuicio de cualquier instrumento internacional o legislación nacional que contenga o pueda contener disposiciones de mayor alcance" ${ }^{28}$. Ambos numerales serán de valiosa ayuda para la propuesta trazada en un comienzo.

La definición se extiende, a partir de la consagración de un modelo de Estado -el democrático de derecho-, por el rico campo de la política y abarca también sus marcas jurídicas, en sus distintas variantes. Para ello se debe tener en especial consideración, como espero poder haber aclarado, que este tema no admite margen de apreciación alguno. Como en seguida se verá, la Corte Europea de Derechos Humanos ha sido constante respecto del alcance de la prohibición y la elasticidad de actos que reprueban una embestida o desafío frente a sus términos.

Mientras que se tejió una red muy consistente y extendida hacia los Estados partes de la Convención en una enorme temática, solidaria con la soberanía política y obvia o circular en tal sentido ${ }^{29}$, de modo tal que existía libertad (reglada) en lo que hacía a fuentes y seguros de protección de los derechos fundamentales ${ }^{30}$, la recogió inmediatamente y sin contradicción en el tema de convocatoria. Así surgió la tesis del deber -yo prefiero obligación- negativo: la absoluta prohibición del art. 3 del instrumento es acompañada por la guía de su intérprete, en cuanto a que cualquier persona privada de su libertad, no debe padecer el uso de la fuerza física sino en la medida de lo estrictamente necesario, de suerte que esa conducta no afecte la dignidad personal y el principio establecido en el Tratado ${ }^{31}$. También la del positivo: el Tribunal reitera que es preciso proteger la vida bajo el art. 2 en conjunción con el compromiso general primario bajo el art. 1, incluso en el recurso a la violencia estatal ${ }^{32}$. Por esa razón surge la imposición de investigar la inobservancia de la regla por funcionarios, los que no deben tener conexión con los sospechados de tortura ${ }^{33}$. Justamente con ello, en tal delicada materia, se dibuja un puente entre las dos caras: es la aclaración de cualquier episodio, lo que separará

${ }^{28}{ }_{I}$. , art. 1.2.

${ }^{29}$ Cfr. ECHR, Z. v. Finland, app. 22009/93, rta. 25/02/1997, dis. III.

${ }^{30}$ Por vía de la ingenieria complementaria o subsidiaria y el rol primario de los Estados partes. Cfr. ECHR., Lithgow and others $v$. United Kingdom, app. 9006/80;9262/81; 9263/81; 9265/81; 9266/81; 9313/81; $9405 / 81$, rta. 8/7/1986, ap. 205 y su cita.

${ }^{31}$ Cfr. ECHR, Aktas v. Turkey (judgment), op. cit., ap. 311 y las citas que allí se hacen: Tekin v. Turkey (judgment), rta. 9/6/1998, Reports 1998-IV, p. 1517, ap. 52, y Labita v. Italy (Grand Chamber), app. 26772/95, ap. 120, ECHR. 2000-IV.

${ }^{32}$ Los Estados partes están obligados a hacerse de los medios para volver efectivos los derechos establecidos en la Convención. Cfr. ECHR, mutatis mutandi no (apenas) en la reparación sino en la prevención de violaciones, Kaya v. Turkey (judgment), ap. 105, app. 22729/93, rta. 19/2/1998.

${ }^{33}$ Cfr. ECHR, Gülec v. Turkey, ap. 81y ss., app. 21593/93, rta. 27/7/98. 
la fuerza en un Estado de derecho, de otro que no lo sea. Todo dependerá de las circunstancias ${ }^{34}$.

Se dijeron todavía más cosas. Desde que la tortura es una suerte de administración en la causación de dolor y con un escalón más bajo también los tratos inhumanos o degradantes, la Corte encontró que ello era opuesto a la dignidad humana: la reflexión fluye, por ejemplo, frente a un correccionalismo sobre menores de edad, a los que los funcionarios -los policías o agentes penitenciarios en particular- podían presionar o proporcionarles castigos corporales ${ }^{35}$. Por otra parte, la decisión en el empleo de técnicas que (des)calificaban cuanto humillantes -emparentado a lo psicológico- y desgastantes -vinculado a lo físico- como método de tratamiento y enfrentamiento a agentes terroristas, en el marco de una batería de medidas que referían a un problema político (también nutrido de otros ingredientes, como ser la religión, el independentismo o separatismo y su manifestación ascendente, etc.), que no podía aceptársela tal y como se la ejecutó, en el nivel de las máximas autoridades y, de ahí, hasta sus propios subordinados ${ }^{36}$.

Sin embargo, pese a lo anterior, la firmeza está lejos de ser lograda, producto de grietas fácticas que amenazan seriamente la perdurabilidad de una idea de estructura normativa. A partir de sus dos básicas salidas, por lo general, tal y como entonces sucedía en el pasado, la tortura es empleada, justificada, pensada y fatalmente resignada, como sanción legal, paralegal o ilegal, o bien como instrumento de prueba, con la alternativa de que se persiga con ella la verdad de algo, o que incluso no interese para nada ${ }^{37}$.

En la teoría de la pena subyace, como en la política, la alternatividad, lógicamente excluyente entre sí, en los extremos del bien y el mal. Este maniqueísmo propone, desde la tensión entre lo social e individual, un contenido forzosamente negativo del derecho penal: es la reacción y la represión, la brutalidad y el desprecio por los autores o partícipes del delito ${ }^{38}$. Semejante concepción empuja hacia el abandono de la fracción de la esfera de la ciencia jurídica pública, por la que se fundamenta y decide el dirty work. No obstante, ello no podría ser consentido.

Por un lado, porque el merecimiento por la desaprobación fundamental frente a un hecho punible, no trae consigo avasallar la dignidad personal, lo que

\footnotetext{
${ }^{34}$ Cfr. ECHR, Kaya v. Turkey, op. cit., ap. 87.

${ }^{35}$ Cfr. ECHR, Tyrer v. United Kingdom, app. 5856/72, rta. 25/4/78, ap. 30, 40.

${ }^{36}$ Cfr. ECHR, Ireland v. United Kingdom, app. 5310/71, rta. 18/1/78, ap. 159.

${ }^{37}$ Cfr. CASSese, Antonio (2008): I dirittti umani oggi, (Laterza, Roma-Bari), pp. 172 y ss.

${ }^{38}$ Cfr. Hassemer, Winfried (2007): Direito Penal libertario (Freiheitliches Strafrecht, trad. Greve, Regina, Belo Horizonte, Del Rey), pp. 70 y ss.
} 
además no resiste la confrontación con la Convención correspondiente. Hay que considerar que la Sühnetheorie se apoya en la autoreconciliación del culpable ${ }^{39}$, lo que presenta dificultades de todo tipo, en especial (aunque no apenas) para su empleo en el terrorismo. Si, desde la partida en la dignitas, se asume que la atención por las demás personas es tanta como la que se puede exigir de aquéllas a mí, tal valoración no tiene costo ni un equivalente al objeto de estima; de forma tal que una negación se extiende más allá del caso particular, por ser persona: incluso al autor del delito. Su convencimiento sobre la base que determina su decisión no es oponible, justificable ni excusable con fundamento en su posibilidad de reconocimiento en la crítica de la razón jurídica de los derechos humanos pero, a propósito, serían éstos los que por la tortura impedirían convertirlo en algo distinto de lo que $\mathrm{es}^{40}$. O sea, hacerle un daño o inyectar dolor no es tanto para que reflexione y lamente su propia perdición ${ }^{41}$, sino para que la abandone y la cambie por la que adopta la mayoría. Solamente entonces podrá consumirse, expiar y renacer, por la condena, desde lo que hizo ${ }^{42}$. Nunca antes. La Vergeltung es compleja por igual puesto que habría que prepararse a dar, como consecuencia o respuesta del delito, el suplicio. En clave con ello, sobresalen algunos de los caracteres de la pena-que supuestamente marcan una evolución de la civilización- que son imposibles de darse por cumplidos: sería exacto que proporcionalidad y determinación cuentan con escollos desde su punto de largada, dado que no se podría (re)actuar sobre alguien en incompatibilidad con la condición de humanidad ${ }^{43}$. A no ser que se esté dispuesto a abandonarla en devolución pero, se supone, esta es la distinción racional de la retribución penal que la distancia de la emoción de la venganza ${ }^{44}$. Sin perjuicio de ello, si se cree que hace parte de prevención general negativa o intimidación, se subestima (por no decir desprecia) la percepción subjetiva de los que la tienen que padecer, sin borrar lo recién lo anotado ${ }^{45}$. El nudo que descansa, superándose la historia, en castigar menos pero mejor ${ }^{46} \mathrm{y}$ orientada a su eficacia,

\footnotetext{
${ }^{39}$ Cfr. Kaufmann, Arthur (1976), pp. 200 y ss.

${ }^{40}$ Mayor desarrollo de estos temas en Machado Pelloni, Fernando M., Desobediencia \& delito, tesis doctoral, inédita todavía. Cabe para las dos notas subsiguientes.

${ }^{41}$ Lo cual es un absurdo fáctico.

${ }^{42}$ Este también es otro sinsentido.

${ }^{43}$ Cfr. KanT, Immanuel (1999), p. 52.

${ }^{44}$ Cfr. Mantovani, Ferrando (1984), p. 405.

${ }^{45}$ Cfr. Fiandaca, G.-Musco, E. (2001), p. 660. Aunque sea eficaz para la gran mayoría, los destinatarios serían partes de minorías. Sobre esto, Mantovani, Ferrando (1988), pp. 692-693.

${ }^{46}$ Cfr. Foucault, Michel (2008), p. 107: “...un crimen que espanta la conciencia es a menudo de un efecto menor que una fechoría que todo el mundo tolera y se siente dispuesto a imitar”.
} 
entonces continuaría intacto por no motivar ni ser idóneo en ello ${ }^{47}$; salvo que la imposición sea la propia afirmación normativa ${ }^{48}$, lo que devuelve todo a su $\operatorname{costo}^{49}$. Por el otro, la necesidad de sanción entablada a partir del responsable por un injusto culpable supone también contenciones, más allá de la antigua y prohibida brutalidad soberana que sellaba el poder sobre el cuerpo ${ }^{50}$, dado que la resocialización o corrección por la fuerza tropieza con el factor resultado, al menos si persigue que alguien deje de obrar lo que tiene como imperativo de hacer $^{51}$.

En el reverso de una confianza en el sistema que no se puede lograr ${ }^{52}$, y aunque no sea la vía, subyace además que la limitación que aquél en la materia tiene, resulta, por cierto, ninguna y la arbitrariedad penal no está en su concepción ${ }^{53}$. A lo último se vuelve a sumar la proporcionalidad, inherente al Estado de derecho, que plantea objeciones en cuanto al contenido, porque una persona no puede ser reformada coactivamente, o que lo sea con un sello de discriminación por autor ${ }^{54}$. No significa esto que no pueda distinguirse según el puente que une hecho e individuo, sino que por el primero se quiten los frenos contenedores del modelo estatal frente al segundo. Nada más pero nada menos. En efecto, la desaprobación e incluso el total y profundo rechazo al orden jurídico habilitaría según una prevención positiva especial tratamientos superadores, pero jamás esto podría ir más allá de la propia

\footnotetext{
${ }^{47}$ Se supone que son problemas también. Cfr. Bitencourt, Cezar R. (2008), p. 92.

${ }^{48}$ Fundamentado a partir de la Aufhebung hegeliana. A partir de no tomar la retribución de la pena como un bien ex post, sino a partir de la norma, se critica que participe de aquella teoría y se la ha denominado rehabilitacionista. Cfr. Amengual Coll, Gabriel (2001), pp. 148 y ss. De cualquier modo, la versión es altamente criticable.

${ }^{49}$ También se interroga, con razón, si con una amenaza así el Estado puede hacer valer su autoridad. Cfr. Antolisei, Francesco (2000), p. 688.

${ }^{50}$ Cfr. Foucault, Michel (2008), p. 60. Porque actualmente no podría pasar, cuanto menos en teoría.

${ }^{51}$ Fundamentalmente en el caso del fanático.

52 Sobre confianza, JaKobs, Gunther (1997), pp. 30, y 44 y ss. También Antolisei, Francesco (2000), p. 691.

${ }^{53}$ Cfr. Bitencourt, Cezar R. (2008), p. 101. Hay ordenamientos que han preferido reglas primarias clarísimas: "Le pene non possono consistere in trattamenti contrari al senso di umanità e devono tendere alla rieducazione del condannato" (art. 27.3 CI) o "Nessuno può essere obbligato a un determinato trattamento sanitario se non per disposizione di legge. La legge non può in nessun caso violare i limiti imposti dal rispetto della persona umana" (art. 32.2 id.). Esto supone precisiones de justificación. Cfr. MantovanI, Ferrando (1988), p. 622. También para el caso español, sobre los arts. 15, 25.2 CE. Cfr. Gracia Martín, L.-Boldova Pasamar, M.A.-Alastuey Bodón, C. (2000), p. 67.

${ }^{54}$ Principio de toda teoría racional. Cfr. FiandaCa, G.-Musco, E. (2001), pp. 654 y ss (2006, pp. 694 y ss.); Gracia Martín, L.-Boldova Pasamar, M.A.-Alastuey Bodón, C. (2000), p. 62.
} 
dignidad humana, además de trasladar el conflicto al perímetro de la teoría del delito, en la correspondencia entre culpabilidad, reprochabilidad y pena ${ }^{55}$.

El órgano de interpretación de la Convención Europea dijo, sin importar el orden jurídico que la pena vendría mantener y que en el caso iba a resultar la muerte por adulterio, que: “...teniendo en cuenta el hecho de que el Artículo 3 envuelve uno de los valores más fundamentales de una sociedad democrática y prohíbe la tortura o tratamiento o castigo inhumano o de degradación en términos absolutos, se debe conducir necesariamente un escrutinio riguroso en la demanda de un individuo cuya sola deportación a un tercer país lo expondrá al tratamiento prohibido por la disposición" 56 . Si tal definición es una señal satélite en el costado de las teorías retribucionistas, cabe lo propio con las relativas: "El Tribunal ha tensionado constantemente que el sufrimiento y la humillación implicados (en la consecuencia jurídica) deben en cualquier caso ir más allá de ese elemento inevitable del sufrimiento o de la mortificación conectada con una forma dada de tratamiento o de castigo legítimo. Las medidas que privan a una persona de su libertad pueden implicar a menudo tal elemento. De acuerdo con el Artículo 3 de la Convención, el Estado debe asegurarse de que detengan a una persona bajo condiciones que sean compatibles con el respeto por su dignidad humana y de que la manera y el método de la ejecución de la medida no lo sujeten a la señal de socorro o a la dificultad que excede el nivel inevitable de sufrimiento inherente en la detención" ${ }^{57}$. Aquí, como en otros supuestos, asumen una gran importancia las circunstancias del caso particular: extensión, efectos físicos y psicológicos, y en algunos casos, por último, sexo, edad y estado mental del condenado ${ }^{58}$. Todos factores que terminan siendo vitales en ejecución penal.

Las condiciones en que lo último importa no escapan a la prohibición. No hace tanto se procedió con un estricto escrutinio sobre la situación carcelaria en donde no había espacio para la dignidad: “...bajo esta previsión el Estado debe asegurarse que una persona es detenida en condiciones que son compatibles y las cuales son coherentes con el respeto por su humanidad, de manera que método de ejecución o no, no sometiéndolo (al denunciante) a maltrato por conducta de

\footnotetext{
${ }^{55}$ En el sentido clásico adoptado por el Tribunal Supremo alemán, BGHSt 2,200: "Schuld ist Vorwerfbarkeit. Mit dem Unwerturteil der Schuld wird dem Täter vorgeworfen, daB er sich nicht rechtmäBig verhalten, daB er sich für das Unrecht entschieden hat, obwohl er sich rechtmäBig verhalten, sich für das Recht hätte enstscheiden konnen". Concuerda, Roxin, Claus (1997), p. 99.

${ }^{56}$ Cfr. ECHR., Jabari v. Turkey, app. 40035/98, rta. 11/7/00, ap. 39. En tal sentido la ley del requirente Irán, art. $102 \mathrm{CP}$ : "El apedrear a un adúltero o a una adúltera será realizado mientras que cada uno se coloca en un agujero y se cubre con el suelo, él hasta su cintura y ella hasta una línea sobre sus pechos."

${ }^{57}$ Cfr. ECHR., Kafkaris v. Cyprus, app. 21906/04, rta. 12/2/08, ap. 96.

${ }^{58}$ Cfr. ECHR., Kafkaris v. Cyprus, op. cit., ap. 95.
} 
una intensidad que excede el nivel de sufrimiento inherente a la detención, por lo que la práctica hasta allí, salud y recuperación están adecuadamente seguros" 59 . Ahora, sin perjuicio de lo anterior, el Tribunal atacó los argumentos del Estado sobre el exceso de la pretensión: (tras tener localizado el conflicto) de medir los siete metros cuadrados que se infieren de la Conveción del caso por prisionero, advirtió que ante sí tenía un caso de apenas dos y que -por no responder- la demandada consentía que tan poco espacio era una vulneración al art. $3^{60}$. No se advierten excesos en la defensa y promoción de los derechos y de sus titulares: basta mencionar que por ir y deber compartir un baño en presencia de otro interno no hay infracción, como por su lado si, al contrario, cuando se procede con aislamiento o discriminación en un área carcelaria ${ }^{61}$. Más allá de cuanto precede, recuérdese que influyen las circunstancias de cada presentante: la nula higiene-por cañerías afectadas que dejaban agua en la celda-y adelgazamiento de más de quince kilogramos de un denunciante, hizo acoger la demanda en otro ${ }^{62}$. Estos supuestos fácticos -comprendidos en la jurisprudencia- sobran, sin que sea atenuante el comportamiento (ex-ante) de la víctima (otrora sujeto activo de un delito) de la agresión a los derechos humanos ${ }^{63}$.

Allí en el Viejo o aquí en el Nuevo Mundo, ninguna duda puede caber que nada positivo puede surgir de lugares donde no hay recuerdo de la idea de dignidad. De un ángulo, porque la pretensión de seguridad pública respecto que autores de hechos punibles no pongan en peligro bienes jurídicos penalmente relevantes, en condiciones infrahumanas de vida, no se puede cumplir, habida cuenta que tal estado de situación, está probado en Argentina y Brasil -sin perjuicio de sus características propias-, genera el control de la ejecución del delito desde adentro. Por el otro, lejos está semejante diagnóstico de empalmar con la tranquilidad interna que se supone sobre la vida y la salud de los internos, y más distante que de ahí alguien pueda ser resocializado grosso modo ${ }^{64}$.

\footnotetext{
${ }^{59}$ Cfr. ECHR., Mayzit v. Russia, app. 63378/00, rta. 20/1/05, ap. 38.

${ }^{60}$ Cfr. ECHR., Mayzit v. Russia, op. cit., 39, 40.

${ }^{61}$ Cfr. ECHR., Peers v. Greece, app. 28524/95, rta.19/4/01, ap. 75.

${ }^{62}$ Cfr. ECHR., Novoselov v. Russia, app. 66460/01, rta. 2/9/05, ap. 41. Todo sin perjuicio que también estaban los restos de sobrepoblación, falta de espacio y de camas también.

${ }^{63}$ Cfr. ECHR., Labzov v. Russia, app. 62208/00, rta. 16/6/05, ap. 41 y ss. Humillación por doquier, establecimientos impresentables, no poder dormir, entre una cuenta interminable de infracciones al art. 3.

${ }^{64}$ Cfr. Macaulay, Fiona (2007): "Os centros de resocializacáo no estado de Sáo Paulo: Estado e sociedade civil em um novo paradigma de administracáo prisional e de reintegracáo de ofensores", Revista do Estudos Criminais, $\mathrm{N}^{\circ}$ 26, (Porto Alegre-Rio Grande do Sul), p. 64. En el caso argentino, sobre lo que ocurre basta litigar y, quizás por esta razón, es extraño pero casi cualquier cosa que se diga en los medios de comunicación sobre la prisión sea, para variar, vecina a la verdad.
} 
La Corte Europea no salteó, al fin de cuentas, su regla en lo que hace a la investigación o judicialización de hechos punibles gravísimos: nadie pierde de vista que el proceso penal se ocupa de aplicar penas y separar desde el derecho, lo punible de lo que no lo es, en cualquiera de sus salidas ${ }^{65}$. Al contrario, la reafirmó, más allá de cualquier flexibilización intentada. No obstante, hubo objeción. De cara al consecuencialismo sin duda existió y subsistió una contribución mayúscula, de ahí todo lo demás. Mi imputación radica en el exprimido del pensamiento utilitarista, por la que se pregonaba que el recurso a la tortura es, si se lo ve de modo estricto, mucho mejor que la propia sanción: es que el sufrimiento cae cuando el que lo recibe deja de resistirse a lo que le exigen de hacer o dejar de hacer ${ }^{66}$. La seguridad pública debe, no obstante, correr un serio peligro para buscar cobertura en esta herramienta que, por su delicadeza, no debía emplearse sino cuando se supiera que su perjuicio como tal no se compadecería con su frustración.

A pesar de la minimización de la tortura, siquiera la evitación de un resultado de magnitud tranquilizaba en lo que a una generalización de la realización de aquélla pudiera tener lugar por permeabilidad, como tener prueba de que aplicársela a alguien hará una diferencia -o sea prueba para proceder con un medio probatorio-: en especial que dirá lo que sabe cuando se le pregunte por un caso ${ }^{67}$, al margen de su (in)discutible (in)valide ${ }^{68}$. La jurisprudencia, sin embargo, se mantuvo. Así ocurrió con un acusado de homicidio en violentos hechos teñidos por políticas de liberación nacional, en territorio bajo soberanía francesa. Los tribunales nacionales, también fue la posición del gobierno durante el proceso internacional, acentuaron la necesidad de proteger el orden público de los perjuicios derivados del comportamiento del demandante. Sin embargo: "El Tribunal acepta, por la razón de las graves particularidades y la reacción popular contra

${ }^{65}$ Cfr. Beling, Ernst von (1913): Grenzlinien zwischen Recht und Unrecht in der Ausübung der Strafrechtspflege, (Tübingen J.C.B. Mohr (Paul Siebeck)), p. 16.

${ }^{66}$ Cfr. Bentham, Jeremy (1973), p. 309: "Torture ... is where a person is made to suffer any violent pain of body in order to compel him to do something, which done ... the penal application is immediately made to cease".

${ }^{67}$ Cfr. Bentham, Jeremy (1973), p. 316. Lo leí cuestionado por el historiador del que hice mención a un comienzo. Cfr. Burleigh, Michael, "Why we must have an inquiry into ministers'collusion in torture", op. cit., p. 14. No hace mucho se encontró un manual de célula terrorista fundamentalista e incluía bajo tortura decir cualquier cosa, para más tarde inmediatamente negarla, entre un centenar de recomendaciones de todo tipo a distintos niveles de organización. Ampliar, Spataro, Armando (2007): Terrorismo e crimine transnazionale: aspetti giuridici e premesse socio organizzative del fenomeno, (Roma, Consiglio Superiore della Magistratura), p. 13.

${ }^{68}$ No hace falta ser un estudioso del derecho para darse cuenta. Cfr. BurleIGH, Michael, "Why we must have an inquiry into ministers' collusion in torture", op. cit., p. 14. Para Brasil, STF ministro relator Sepúlveda Pertenece, HC 69.913-0/RS, Informativo N³6, citado por Moraes, Alexandre De (2006): Dereitos Humanos Fundamentais, op. cit., pp. 107-108. 
ellos, que ciertos delitos llegados a la inquietud social justifiquen una detención preventiva por mucho tiempo..." ${ }^{69}$ pero "no se considera el examen del sistema de custodia policial francés y sus pertinentes reglas ahí o, en este caso, por la extensión y la pertinencia del modo de interrogar al denunciante" 70 . También cabe con imputados sospechados por tráfico de estupefacientes, como en el caso lo fue por heroína y conectada además con la muerte de un par de personas. En esta otra oportunidad, se señaló: "Hacemos especial énfasis en que, respecto de un individuo privado de su libertad, cualquier recurso a la fuerza física el cual no sea estrictamente necesario a su conducta, disminuye la dignidad humana y es en principio una infracción al derecho establecido en el art. 3 de la Convención. Se reitera que las exigencias de una investigación y las dificultades inherentes en la lucha contra el crimen no puede justificar hacer lugar en los límites sobre la protección de la integridad física de los individuos" ${ }^{\prime 1}$.

La incidencia, en este trayecto, no se acaba allí. Se extiende hacia lo psicológico, que en la magnitud de las consecuencias, es acaso una de las más irreparables: "La agresión sexual de una detenida por un agente estatal debe ser considerada como una forma especialmente grave y horrorosa de tratamiento dado al caso, en el que el agresor puede explotar la vulnerabilidad y la línea de resistencia de su víctima... ella fue prisionera por un período de más de tres días en la que ha sido desorientada y distraída, sin poder ver, y en un constante estado de dolor físico y angustia mental, logrado por enfrentamientos de la administración durante el interrogatorio y aprehensión que le sucediera”, lo que es una violación a la Convención ${ }^{72}$.

\section{TOMA DE POSICIÓN PRECAUTORIA.}

\section{A SU VEZ, UN ESQUEMA CLASIFICATORIO: ANÁLISIS Y CRÍTICA}

Más allá de lo compacta que resultaría ser la prohibición, la jurisprudencia de la Corte Europea deja al descubierto el incumplimiento de la obligación por los que tienen a su cargo el rol primario de protección de los derechos fundamentales. En todos los niveles estatales, en cualquier área de la que es parte la prohibición según el panorama precedente. Por ello, a propósito de éste, unas pocas cuestiones aditivas : I. se supone y efectivamente es cierto que la tortura implica o cuenta con un plus respecto de los tratos crueles, inhumanos y degradantes según la jurispru-

${ }^{69}$ Cfr. ECHR., Tomasi v. France, app. 12850/87, rta. 27/8/92, ap. 91.

${ }^{70}$ Cfr. ECHR., Tomasi v. France, op. cit., ap. 115. Más allá de la constatación médica que existía.

${ }^{71}$ Cfr. ECHR., Ribitsch v. Austria, app. 18896/91, rta. 4/12/95, ap. 38. Sobre la crítica del proceso como cuestión de autoridad, y su relación con lo inquisitivo, Mantovani, Ferrando (1984): Il problema..., op. cit., p. 631.

${ }^{72}$ Cfr. ECHR., Aydin v. Turkey, app. 57/1996/676/866, rta. 25/9/97, ap. 83-84. 
dencia pero no están distinguidos porque, en mi opinión al menos, aquélla no zanja la distinción ${ }^{73}$; II. la observación del problema y su dinámica ha empujado a reconsiderar posiciones adoptadas en orden a los comportamientos, de modo que cuanto en una época pudo no ser tortura, tiempo más tarde lo era y, desde la lógica, lo que antes no fue trato cruel inhumano y degradante, hoy bien puede serlo, y III. la seriedad de la cuestión y su amplio espectro de irradiación debe conducir a estar en guardia respecto de cualquier comportamiento, habitual o inusual, que pueda alterar el núcleo de dignidad cuya defensa por la fuerza normativa se persigue. Dos casos, pueden prestar su ayuda.

In primis se recoge el precedente característico en lo que hace a la lucha contra el terrorismo. Éste encerraba un volumen de medidas de coerción extrema en la escalada armada entre nacionalistas y religiosos irlandeses e ingleses ${ }^{74}$. Las técnicas que se emplearon se limitaron a cinco que -aisladas o combinadas- se hicieron en extremo famosas, a propósito, por no ser tortura: i.- una consistía en que los sospechosos permanecieran de pie frente a una pared por intervalos de entre veinte a treinta horas, lo que causaba dolor físico y arrojaba personas exhaustas; ii.- aislamiento; iii.- privación del sueño; iv.- contaminación sonora permanente; v.- restricción de alimentos o agua, o ambas ${ }^{75}$. Esto ilustraba sobre tratamientos inhumanos y degradantes ${ }^{76}$.

No obstante, acontece que tiempo más tarde al caso que comenzó con la línea de diferencia separatista entre tortura y tratos crueles e inhumanos, los últimos con enormes datos de la jurisprudencia, aparecen con cierta dinámica o en un contexto que agravan los actos denunciados como específicos de tortura por la deliberada y específica causación de dolor físico o psicológico ${ }^{77}$.

In secundis e integrado al antecedente, se asiste a la determinación de la tortura no ya por infligir dolor físico y mental para hacer confesar u obtener confesión del imputado -en la luz de la Convención-, sino por llevar a la angustia, inferioridad, capaz de quebrar su resistencia física y moral: “...el Tratado es un 'Instrumento vivo el cual debe ser interpretado a la luz de las condiciones del presente día'”, por lo que la Corte estima "...considerando ciertos actos que fueron clasificados en el pasado como 'tratamiento inhumano y degradante' y contrario a 'tortura' que podría clasificarse con distinción en el futuro. Ello toma la visión que el

\footnotetext{
${ }^{73}$ Cfr. Harris, D. J.-O’Boyle, M.-Bates, E. P.-Buckley, C.M. (2009), p. 91.

${ }^{74}$ Cfr. ECHR., Ireland v. The United Kingdom, app. 5310/71, rta. 18/1/78.

${ }^{75}$ Cfr. ECHR., Ireland v. The United Kingdom, op. cit., ap. 104. Luego abandonadas y nunca más reimplantadas, ap. 153.

${ }^{76}$ Cfr. ECHR., Ireland v. The United Kingdom, op. cit., ap. 165.

${ }^{77}$ Cfr. ECHR., Aydin v. Turkey, op. cit., ap. 82 por ejemplo.
} 
incremento del alto standard requerido en el área de protección de los derechos humanos y las libertades fundamentales correspondiente, inevitablemente cuente con gran firmeza en la profundización de los valores fundamentales de las sociedades democráticas" ${ }^{78}$. Semejante perímetro permite correr la prevención o reparación para el art. 3, incluso ante una extradición pasiva cuya pena prometida sería la sanción capital, "...donde serias razones para creer que un individuo sería allá tomado, en el Estado requirente, como un trato contrario" ${ }^{79}$. Por otra parte, resulta una válida conclusión repensar que es perfectamente admisible - mutatis mutandi- que un (clásico) incumplimiento (por quebrantamiento) de las formas del debido proceso legal, según su naturaleza, modo de comisión e ilegalidad causal por sus resultados y efectos, abandone ese escenario y se traslade a un (nuevo) maltrato (por infracción) en términos convencionales: piénsese no solamente en una confesión extrajudicial, sino también en una (degradación no) "presunta" renuncia al derecho fundamental a comunicarse el sospechoso con su defensor, tras horas de incomunicación y hostilidad a instancias de medidas de coerción legales ${ }^{80}$.

Aclarado lo que es, iré sobre lo que no debe ser. No faltan, es lo que anuncié, voces de todo tipo, en contra de la prohibición. Veré las tesis con las antítesis. Dos cuadros orientarán la distinción básica posible de la que se desprenderán múltiples combinaciones, a lo que me opondré:

\section{Cuadro A CA}

\begin{tabular}{|c|c|}
\hline Política e Interna PeI & Política y Externa PyE \\
\hline Incidencia Procesal IP: un modo de & Incidencia Procesal IP: un modo de \\
atender la seguridad pública. & ganar una guerra que alteró la paz. \\
Tesis PeI - IP & Tesis PyE - IP \\
Tranquilidad frente al Terror por el & Exportar democracia e Importar \\
Terror & Tortura \\
\hline
\end{tabular}

\footnotetext{
${ }^{78}$ Cfr. ECHR., Selmouni v. France, app. 25803/94, rta. 26/7/99, ap. 101 y ss. Este caso sería corriente de algunos establecimientos penitenciarios en los que se humilla sexualmente al allí alojado, por palabra, por abuso físico.

${ }^{79}$ Cfr. ECHR., Soering v. The United Kigndom, app. 14038/88, rta. 7/7/89, ap. 82. Sobre asilo, ECHR., Said v. Netherlands, app. 2345/02, rta. 5/10/05, ap. 46. La única carga es la demostración por persuación.

${ }^{80}$ Degradar es expresión de miedo, ansia e inferioridad con el fin de humillar, quebrar o romper una resistencia física o moral de quien soporta el trato. Cfr. ECHR., Ireland v. The United Kingdom, op. cit., ap. 167. Lo cual deriva de la vulnerabilidad de quien está detenido, la que es mayor si aquélla es ilegal o producto de desproporción. Cfr. doctrina, ECHR., Ribitsch v. Austria, op. cit., ap. 36.
} 
Cuadro B CB

\begin{tabular}{|c|c|}
\hline Jurídica e Interna JeI & Jurídica y Externa JyE \\
\hline $\begin{array}{c}\text { Incidencia Sustantiva IS: un modo de } \\
\text { interpretar la actividad estatal. } \\
\text { Tesis JeI - IS }\end{array}$ & $\begin{array}{c}\text { Incidencia Sustantiva IS: un modo de } \\
\text { avalar la cooperación internacional. }\end{array}$ \\
$\begin{array}{c}\text { Legítima defensa / Estado de necesidad }- \text { IS } \\
\text { Preventivas y Putativas }\end{array}$ & $\begin{array}{c}\text { Pacta sunt servanda bi-multilateral } \\
\text { sin dignidad }\end{array}$ \\
\hline
\end{tabular}

El CA plantea un conjunto básico de resolución política a un problema planteado únicamente a ese nivel, con respuestas pensadas en tal esfera con rechazo, desatención o ignorancia hacia los problemas jurídicos. De ahí que PeI y PyE, con sus particularidades, se concentran en lo que la tortura o los tratos crueles, inhumanos o degradantes pueden aportar por intermedio de la IP: datos, que una vez procesados se vestirán de información. Por el contrario, el CB sin independizarse de la política, hace un esfuerzo por interpretarla jurídicamente, tanto que JeI y JyE hacen que el impacto intente una base de operaciones en la teoría jurídica y por tal razón la IS: se puede proceder incluso contra la Convención. Entiéndase que tampoco opera el derecho como debería -limitar-, sino para justificar, más allá de un conflicto importante como sucede con la relación entre este acto y la verdad.

La tesis (CA)PeI-IP la denomino: Tranquilidad frente al terror por el terror. Señalé ut-supra como sucedió frente a las incursiones cada vez mayores del Ejército Revolucionario Irlandés (IRA) ${ }^{81}$. Sintéticamente, recurrieron a "sus" técnicas desplegadas a partir de poderes reglamentados especialmente y las razones para ello fueron lo inadecuado de los procedimientos normales, que para los restantes casos eran suficiente para restablecer la paz y el orden. Derivado de lo previo, también se perseguía cierta intimidación a la población, para obtener confesiones o evidencias y, al fin, el conflicto en el control de las rutas de escape entre ambos Estados, norte y $\operatorname{sur}^{82}$. La Corte sentenció como "una práctica incompatible con la Convención... la acumulación de sucesos idénticos o análogos lo suficientemente numerosos e interconectados..." como para ser estimados aislados o excepciones a un sistema: es inconcebible de las más altas autoridades de un Estado parte que sus subordinados sean guiados a no respetar la regla ${ }^{83}$. La antitesis resulta de asegurar

\footnotetext{
${ }^{81}$ Cfr. ECHR., Ireland v. The United Kingdom, op. cit., ap. 11 y ss. Probablemente, el incremento de bombas estalladas que pasó de 8 a 155 en apenas un año, 1969-1970, fue acaso de uno de los más serios factores para las disposiciones de emergencia; ap. 29.

${ }^{82}$ Cfr. ECHR., Ireland v. The United Kingdom, op. cit., ap. 36.

${ }^{83}$ Cfr. ECHR., Ireland v. The United Kingdom, op. cit., ap. 159.
} 
los beneficios desde lo colectivo, para lo cual desde el campo de las obligaciones las medidas no pueden ser prejuiciosas respecto de las personas (connacionales, para la ocasión): los redactores del Tratado dejaron en claro que derechos y libertades serían directamente asegurados a cualquiera en la jurisdicción de los Estados parte, de acuerdo al art. ${ }^{84}$. La síntesis resultó en que aproximadamente más de cincuenta casos comprobados de violaciones contra la prohibición de tratos crueles, inhumanos y degradantes, verificaron que la política interior sin derechos humanos es incluso anti-consecuencialista en lo que a lograr su autofinalidad eminentemente fáctica lo pueda definir ${ }^{85}$.

En su faceta hacia fuera, la idea (CA)PyE-IP es actualmente la Exportación de la Democracia por la Importación de la Tortura. Sin duda, el radical obstáculo de este enfoque es que la Corte Europea -a lo largo de la jurisprudencia citada- ha sido constante y coherente en señalar, justamente, que la prohibición del art. 3 de la Convención es acaso uno de los valores más importantes para una sociedad democrática. Por ello el traslado de esta forma de gobierno por vía de la tortura, los tratos crueles, inhumanos y degradantes es, por decirlo con simpleza, un sinsentido, una contradicción de la proporción de una burla, irrespetuosa con la propia dignidad humana ${ }^{86}$. En Europa lo han advertido algunas voces (supongo, políticamente incorrectas) cuando el Parlamento comunitario señaló en un informe que superada la Guerrá fría se asiste a una deuda democrática ${ }^{87}$.

Probablemente en el tema de convocatoria y merced a los derechos fundamentales, los planteos PeI y PyE planten un reduccionismo inaceptable, al menos si se tiene en cuenta que resulta inadecuada una tranquilidad interior si desde fuera se comprueba un ataque a la prohibición y, también, que tampoco es idóneo a la democracia hacia el exterior una predica que cuestiona un valor ineludible y esencial a ella, lo cual la pone en riesgo hacia dentro. De hecho nada de ello resulta democrático en el terreno de la igualdad donde tiene su espacio la dignidad: una violación es tal en cualquier lugar del mundo. ${ }^{88}$ Por otra parte, la gran diferencia entre autocracias antiguas y las contemporáneas es que antes la tortura era pública,

\footnotetext{
${ }^{84}$ Cfr. ECHR., Ireland v. The United Kingdom, op. cit., ap. 239.

${ }^{85}$ No ha sido la meta propuesta a un comienzo, aunque podría hacerse todo un estudio sobre la transportación del caso europeo a lo sucedido en Argentina respecto del terrorismo de Estado en el enfrentamiento contra la subversión. En lo pertinente, ampliar (1996): Nunca Más. Informe de la Comisión Nacional sobre la Desaparición de Personas (CONADEP), (BsAs, Eudeba), pp. 54 y ss.

${ }^{86}$ Cfr. CARRIó, Genaro (1973), p. 26. Allí se da una gran argumentación. Limitado al asunto que me convoca, terminante, Spataro, Armando (2007), p. 43.

${ }^{87}$ Cfr. Parliamentary Assembly Eu (2007): Secret detentions and ilegal transfers of detainees involving Council of Europe member states, doc. 11302 rev., ap. 12.

${ }^{88}$ Cfr. Bonanate, Luigi (2004), p. 45.
} 
como expresión máxima del poder a modo de escarmiento y actualmente se la oculta o no se la llama así por ineficiencia en el manejo de aquél y de cara a los problemas, principalmente por la modificación del modelo estatal que supone proceder con ella, punto sobre el cual advertí en un principio y que se revalida aquí frente a una retórica que, como tal, no es nueva ni mucho menos convincente. Así por ejemplo, frente a los conflictos no importa si radican -o no- en el territorio del Estado ni tampoco si lo encaran otras potencias - $\mathrm{u}$ organizaciones-, es un recurso muy común la mención de que todo es guerra -como si ella legitimara actos faltos de un rastro de humanidad- y, con toda seguridad, nada de ello lo es. ${ }^{89}$

Cualquier propuesta que conlleva la violencia en su expresión prepotente, sin una racional contención es antidemocrática y por tal razón es muy difícil que sea patrimonio auténticamente democrático el hecho de la instalación de actos de barbarie: es su contradicción ${ }^{90}$. El enlace del derecho penal con todo esto, el único posible es el de un contenido del mal: la cristalización del dirty work. La distancia con la historia era que previo a la ilustración nadie lo iba a negar, como tampoco se podría eludir que esta versión no tiene una relación válida entre necesidad de punibilidad y ordenamiento criminal, si en un lado están las personas que hacen el tejido social y del otro al Estado en el que viven. ${ }^{91}$ Entonces, fácil es advertir que el mayor obstáculo de la argumentación política es que el enfrentamiento del terrorismo u otra amenaza cualquiera contra los valores de la sociedad que representa el Estado, no puede contestarse con terrorismo territorial o extraterritorial a favor del último ${ }^{92}$.

Por argumentos diferentes, el escudo presuntamente jurídico que se antepone a la trasgresión sobre la inviolabilidad de la dignidad humana no alcanza como cubierta. Desde (CB)JeI-IS se pretende legalizar la acción estatal en el campo de las causales de justificación. La literatura especializada parte del estado de necesidad -genérico- para alcanzar en la legítima defensa -especie- un sendero para incursionar en tentativas de admisión de la tortura, tratos crueles, inhumanos o degradantes. Sin embargo, ab initio los tropiezos -que apenas pueden borronearse por la fuerza política- son enormes si se toma en cuenta la advertencia del derecho internacional de los derechos humanos, recogida -e incluso cuando no- en el orden interno ${ }^{93}$. En este sentido, es por lo menos un importante error estimar que, por intervenciones admisibles - por muy discutibles que todas ellas puedan

\footnotetext{
${ }^{89}$ Cfr. Bonanate, Luigi (2004), p. 87. Sobre los enunciados que explican en detalle porque no es posible entrar en guerra con el terrorismo, pp. 118 y ss.

${ }^{90}$ Cfr. Bonanate, Luigi (2004), pp. 43 ss y 135 y ss.

${ }^{91}$ Cfr. Hassemer, Winfried (2007), p. 77.

${ }^{92}$ Cfr. Bonanate, Luigi (2004), p. 129 con cita del caso de Argentina y Chile.

${ }^{93}$ Sobre el rol de la hermenéutica, Machado Pelloni, Fernando M. (2008).
} 
resultar-, las prácticas analizadas o descritas por la jurisprudencia comunitaria en determinadas circunstancias podría validarse. ${ }^{94}$ Por una parte, porque las detenciones o las consecuencias jurídicas de un hecho punibles e incluso las medidas de seguridad no resisten el confronte de las hipótesis abarcadas por el art. 1 in fine de la Convención contra la Tortura. Sería descontextualizar una base caracterológica y protectora del derecho penal del Estado de derecho para habilitar un modelo distinto ${ }^{95}$. Por la otra, que participa de igual crítica en la medida que la metodología de la ponderación o del balance a la hora de resolver colisión de intereses estudia otros supuestos, en donde las esferas de los atributos básicos resisten -no sin costo alguno- restricciones que no se podrían extender a un área blindada por tratarse del propio núcleo. Obsérvese que la objeción de conciencia o la interrupción de la vida de una persona por nacer, a la par de demostrar (aunque ninguna duda exista) que la libertad no es absoluta, ${ }^{96}$ parejamente no conmueve que infligir dolor contra alguien, como potestad pública y en miras a lograr algo que no podría proponerse, está prohibido. Acaso esto sea parte de la confusión.

Aunque sea dudoso que la Convención Europea de Derechos Humanos no tenga la fuerza normativa que la Constitución alemana ${ }^{97}$, lo que no deja de ser un problema de fuentes, de interpretación o ambos a la vez, resolver si existen excepciones a una regla general e inequívoca respecto de la prohibición de torturas, tratos crueles, inhumanos y degradantes debe hacerse cargo de la obligación primaria -principio de subsidiaridad mediante en un sistema internacional de protección $-{ }^{98}$ en cuanto a que los agentes estatales no procedan en contradicción a la regla ${ }^{99}$. Bajo esta frontera interna, sin escapárseme que es perfectamente posible que un incierto orden jurídico interior trace una autorización expresa, el sistema de un Estado de derecho, a partir de su Norma Fundamental, no las distingue. Tanto peor, aunque se privilegiara el linaje jurídico nacional al internacional, sería contradictorio con este último que manda cuidar y hasta punir comportamientos de agentes que no quiere ni desea, que de uno u otro modo los exima y, en consecuencia, los ampare.

El andamiaje constitucional reconoce para el derecho penal la materialidad y la formalidad en la que la barrera de la dignidad luce limitadora de sus propias

\footnotetext{
${ }^{94}$ Cfr. Gössel, Karl Heinz (2007), p. 24.

${ }^{95}$ Cfr. Carrió, Genaro (1973), p. 26.

${ }^{96}$ Cfr. Gössel, Karl Heinz (2007), pp. 28 y ss.

${ }^{97}$ Cfr. Gössel, Karl Heinz (2007), p. 21. En contra, Satzger, Helmut (2005), p. 142.

${ }^{98}$ Cfr. Satzger, Helmut (2005), p. 143.

${ }^{99}$ En alguna medida se admite que es ineludible; Gössel, Karl Heinz (2007), p. 21.
} 
regla $^{100}$. La proporcionalidad tan arraigada en la dogmática y en el derecho judicial alemán no la erradica incluso en situaciones extremadamente graves, como en el de un atentado terrorista en curso, en donde se cometieron o se ejecutan hechos punibles diversos, como la privación de libertad de los que viajan en un avión que pareciera realmente indicar será estrellado contra un objetivo ${ }^{101}$. Derribar a una aeronave en tal situación no es asimilable, no obstante, a obtener forzosa o dolorosamente algo de alguien, o deliberadamente a agredirle para humillarlo, o desconocer su humanidad por lo que (a veces, presuntamente) hiciera. No digo que aquello sea justificado, lo que sería interés para otra convocatoria: simplemente afirmo que no es un supuesto igual.

Desde el terreno de lo concreto, presento una gráfica exposición distintiva:

Cuadro C CC $\mathrm{C}^{102}$

\begin{tabular}{|c|c|c|}
\hline Estado de Necesidad EN & Legítima Defensa LD & Tortura o Trato Cruel T-T \\
\hline $\begin{array}{l}\text { - Ponderación de bienes } \\
\text { cierta y objetivable, donde } \\
\text { se escoge por inevitable la } \\
\text { lesión del menor por salvar } \\
\text { al mayor; } \\
\text { - Contra una acción de ter- } \\
\text { ceros; } \\
\text { - Es reactiva -lato sensu- y } \\
\text { no depende totalmente del } \\
\text { que actúa. }\end{array}$ & $\begin{array}{l}\text { - Agresión ilegítima y nece- } \\
\text { sidad racional o proporcio- } \\
\text { nal de repeler objetivable; } \\
\text { - Contra una acción de ter- } \\
\text { ceros y sin provocación; } \\
\text { - Es reactiva -stricto sensu- y } \\
\text { no depende totalmente del } \\
\text { que actúa. }\end{array}$ & $\begin{array}{l}\text { - La situación no es objeti- } \\
\text { vable: sea por actos, autores, } \\
\text { circunstancias, y tanto es así } \\
\text { que se apela a ella; } \\
\text { - La acción cierta es propia, } \\
\text { no ajena; } \\
\text { - Es activa y depende exclusi- } \\
\text { vamente del que actúa. }\end{array}$ \\
\hline
\end{tabular}

Frente a las distancias bastante evidentes, la tesis que homologa la tortura o algún tipo de trato cruel, inhumano o degradante en la navegación por las eximentes por justificación, en mi opinión, termina por naufragar. Muchas son las inconsistencias

\footnotetext{
${ }^{100}$ Cfr. SCHMidHÄUSER, Eberhard (1972), p. 41 (ver la relación con el cap. I).

${ }^{101}$ En la Gesetz zur Neurung von Luftsicherheitsaufgaben (11/1/2005), el art. 14 en sus incisos regula las acciones a emprender -disuasivas o de represión, 14.2 y 14.3-a instancias de las fuerzas armadas alemanas, en caso de que un avión estuviere en poder de terroristas.

${ }^{102}$ En líneas de aproximación, en respeto al orden de aparición del CPA., art. 34.3 y 34.6, la parte general de la mayoría de los códigos penales toman en cuenta los elementos que se describen. Cfr. Acerca de los arts. 34 y 32 StGb., exemplo docit, Roxin, Claus (1997), pp. 668 y ss, especialmente 686 para el EN y pp. 605 y ss., en particular 618 y 628 y ss. respecto de LD; también por los arts. 54 y 52 del CPI., Mantovani, Ferrando (1988), pp. 263, y 267 y ss.; por LD pp. 256 y ss, énfasis 258 ; sobre los arts. 24 y 25 CPB., EN y LD, respectivamente, BITENCOURT, Cezar R. (2008), pp. 311, y 315-316 con especial atención y pp. 319, 320-321. Además del codificador argentino, Moreno (H.), Rodolfo (1922): El Código Penal y sus antecedentes, vol. 2, (BsAs., Tommasi), p. 263, véase 264 y pp. 273, 275-276 con requisitos y agresión futura.
} 
de una transportación o las de una asociación como la que se insinúa a través del (CC)EN o de la (CC)LD. Hay que notar, por empezar con la primera causal, que sobre el cotejo de valores es el propio costo de un Estado democrático -según se constatara- el que se sacrificaría para salvar otros, sin desconocer el superlativo interés en la protección o defensa que podrían representar ${ }^{103}$. A pesar de ello, la persistencia de un factor común al EN como a la siguiente LD, aunque operen con alcance independiente, sería que el orden jurídico penal prefiera, porque tiene un interés que tutelar que cede y esto así por cuanto no lo quiere -en los supuestos que con detalle vuelven no punibles determinados actos que por norma lo serían-, un hecho tan extraordinario frente a la volatilidad en la determinación del peligro en base a la amenaza. Tomar una iniciativa así -que no oculta una reacción- no supera ni menos asegura el salvamento, que es la raíz aquí.

En la última causal, lo que se nos quiere presentar como respuesta, tampoco es tal cosa e igual es el punto de lanzamiento de cualquier análisis serio a la invocación de una supuesta LD. La tortura o el maltrato a un ser humano ya supone a una persona total y absolutamente incapacitada per se para una agresión objetiva en curso: a lo sumo, como en la hipótesis de una bomba activada -ticking bomb case-, la cuestión es ya independiente y porque sería preferente ir contra aquella en lugar de aplicar los medios estatales para ubicar o desactivar el artefacto parte de una serie de suposiciones que transitan desde la pereza hasta la ineficiencia en la instrumentación de políticas de prevención del delito y antes de inteligencia, en el procesamiento de datos ${ }^{104}$.

Sea en EN o LD, hay una crítica a tono de antítesis, por la que entonces, no cabe justificar. En efecto, los pesos y contrapesos de las decisiones no son tan fuertes como para poder resistir a la defectuosa fundamentación que se nos quiera presentar, más allá de que un ejemplo extremo como el del artefacto explosivo con detonación programada hubiera sido tenido en cuenta por los británicos para anular derechos fundamentales en Irlanda del Norte ${ }^{10}$. Los propios términos de cualquier escalada son poco contundentes y las razones (a veces, demasiado) fáciles de manipulación: puede ser efectivamente que se trate de una persona que ha puesto en riesgo a otros seres humanos y, esto también, tal vez no. No es inima-

${ }^{103}$ Cfr. CASSESe, Antonio (2008), p. 174.

${ }^{104}$ Hay una mutación de JeI-IS a PyE-IP y que comunica EN o LD con la guerra preventiva. Tal problema excede esta intervención, sin perjuicio de mencionarla. Trataré als Reaktion gegen Unrecht, rechtsmäBiger Krieg y la agresión como crimen internacional a la brevedad en otra empresa. Basta aquí decir que el asunto, contrario a como comúnmente se puede creer, no comenzó después de septiembre 11 de 2001, sino bastante antes. Ampliar, Bowring, Bill (2008), pp. 39 y ss., especialmente 43 y ss.

${ }^{105}$ Cfr. CASSESE, Antonio (2008), pp. 193-194, habilitación que fue inaceptable para la Comisión y la Corte Europea, como he repasado. 
ginable que por la tortura o un maltrato se permita, no sin desconocer el núcleo de la dignidad, que cientos de individuos inocentes puedan estar a salvo aunque, tampoco lo sería, si se fracasara nada impediría continuar con el suplicio hasta que el cuerpo no resista, punto además esencial, por las infinitas combinaciones de resistencias según contexturas o personalidades. Por lo restante, todavía con una acción estatal encaminada en el sentido de realización de la humillación o de la causación del dolor físico o psíquico, no resulta concebible un error de permisión: desde el positivismo no cabe contradicción e incluso con hermenéutica, el principio que opera como el deber ser que consagra el valor lo rechazaría; de modo que el ordenamiento, más allá de situaciones fácticas sin dudas límite, no deja de prohibirlas lo que es público y notorio para el Estado y sus agentes. ${ }^{106}$ Por ello es que no cumplen con una obligación: la incumplen. ${ }^{107}$ En realidad todo, en mi concepto de síntesis, es putativo y debería ser rechazado.

Finalmente (CB) JyE amerita un regreso hacia los puntos más altos del reporte europeo. Es que a lo largo de su exploración se da cuenta que por el seguimiento de compromisos asumidos en la defensa (o cooperación en ella) entre países aliados, se ha procedido a ignorar o violar deliberadamente el derecho internacional de los derechos humanos en la propia Unión Europea, con ocultaciones de operaciones sumamente irregulares, que expuso a cientos de personas a la tortura o a tratos crueles, inhumanos o degradantes.

Lo que se advierte es que bajo la multilateralidad de un instrumento que no es de derechos humanos -como resulta ser la Organización del Tratado del Atlántico Norte (más reconocida como OTAN o NATO en su versión en inglés)-, se ha procedido a un enlace bilateral entre Estados Unidos y países europeos por donde transitan detenidos de alto valor (HVD, High-Value Detainees) en la lucha, que políticos o legislación del primero citan como guerra -que no es-, contra el terrorismo. Ello trajo consigo operaciones con base en distintas ciudades del Viejo Mundo, en las que agencias americanas trabajaron con la asistencia directa o la colaboración de pares de distintas potencias de la Unión: en algunos sitios directamente han garantizado el secreto de lugares de detención, sin interferencia de autoridad alguna. Tal escenario es apenas un fragmento de cuanto sucede con acusados en el programa que no se ha calificado en vano como "muy riguroso": los centros en donde se llevan adelante los interrogatorios se han tildado como auténticos laboratorios (Guantánamo Bay, The Bagram Airfeld-Kabul, Abu GhraibBaghdad, entre los populares, pero los hay desconocidos) ${ }^{108}$.

${ }^{106}$ Cfr. LaCKNer, Karl-KüHL, Kristian (2007), p. 240.

${ }^{107}$ Cfr. sobre la unidad jurídica, Bоввіо, Norberto (1992), p. 189.

${ }^{108}$ Cfr. Parliamentary Assembly EU (2007): Secret detentions and ilegal transfers of detainees..., op. cit., III. 
Bajo estas estrellas, en un cielo decididamente plomizo, se nos presentan "prisioneros fantasmas" (ghost prisioners) que, al decir verdad, lo que tornan inaccesibles, porque no existen, son los derechos fundamentales ${ }^{109}$. Condiciones similares, renovadas a las descriptivamente compendiadas en la jurisprudencia de la Corte Europea de Derechos Humanos ${ }^{110}$, como ser aislamientos con provisiones insuficientes para vivir, sometimientos psicológicos, vigilia permanente o dificultad para posibilitar el sueño, rutinas imposibles de quitar de la memoria de cualquier persona -alterándose alimentación, hábitos religiosos- y exposición a tensión continúa generada a través de cualquier medio, música por ejemplo ${ }^{111}$.

Además hay operativos encubiertos para dar con el paradero de sospechosos de terrorismo. ${ }^{12}$ Sin embargo, esta forma de tesis de cooperación no es la que corresponde a Estados democráticos. Entre estos últimos no cabe male captus bene detentus, ni menos el male detentus, que es lo que se observa. Lo que por derecho corresponde, no es ni podría ser la aplicación de la bilateralidad por vía de la multilateralidad del Tratado de defensa (art. 5) en virtud de un pseudo pacta sunt servanda, más cerca de un enfoque tocado por (CA)PyE que de uno (CB)JyE: al contrario, lo que debe oponerse es la respuesta grociana aut dedere aut judicare, por la que sospechosos de la comisión de un delito cualquiera o individualizados autores o partícipes en él, son requeridos para ser enjuiciados y así, con los presupuestos más elementales del debido proceso legal entre los que cabe el acceso a la tutela judicial efectiva, afrontar consecuencias jurídicas sin mengua de la dignidad personal de los actores involucrados.

${ }^{109}$ Cfr. Parliamentary Assembly EU (2007): Secret detentions and ilegal transfers of detainees..., op. cit., V. En octubre 5 de 2005 el Senado de Estados Unidos aprobó la Enmienda McCain por la cual ningún americano podría tratar en modo horrendo o inaceptable a alguien, pues no podría esperar ser así (mal)tratado un soldado de su país.

${ }^{110}$ Cfr. ECHR., in re Ireland v. United Kingdom, op. cit.

${ }^{111} \mathrm{Al}$ decidirse por la constitucionalidad de la pena capital en Gregg v. Georgia -428 US. 153, 1976-, la argumentación oral por la finalidad de la VIII Enmienda sobre castigos crueles e inusuales dio un diálogo que juzgo revelador entre un juez y el representante del gobierno federal:

Justice Stewart: "What if a state said for the most henious kind of first-degree murders we are going to inflict breaking a man on the wheel and then disemboweling him while he is still alive and then burning him up: What would you say to that?"

(Robert) Bork: "I would say that that the practice is so out of step with modern morality and modern jurisprudence that the state cannot return to it. That kind of torture was precisely what the framers thought they were outlawing when they wrote the cruel and unusual punishments clause".

Ampliar (1993): May It Please the Court..., (NYC, edited by Peter Irons and Stephanie Guitton, The New Press), p. 234.

${ }^{112}$ Cfr. Parliamentary Assembly EU (2007): Secret detentions and ilegal transfers of detainees..., op. cit., VI en el caso de Khaled El-Masri. 


\section{Consideraciones Finales. ObSERVAciones y propuestas}

He intentado -espero haberlo logrado- evidenciar que en las múltiples áreas en que resulta con todo sentido la prohibición de tortura, tratos crueles, inhumanos y degradantes, los comportamientos están tan vivos como en siglos previos a la ilustración que la criticó. La jurisprudencia europea y los estudios que la siguieron apenas nos marcan algunos puntos destacados sobre su cambio. Bajo ningún modo sugieren su desaparición, siquiera su disminución. Por otra parte, con todo el costo de hacer abandono del modelo estatal, la despersonalización del torturado o maltratado no arroja ningún saldo a favor, ya no en el terreno de la validez lo cual es imposible, sino plantado en lo fáctico: la prevención (podría llamársela especial ex ante) del delito no tendrá caso por la conducción del detenido a un lugar secreto o falto de control judicial; no volverá a ese ser humano menos peligroso, más todavía en lo que terrorismo se refiere, habida cuenta de la circulación de la organización. ${ }^{113}$ Tampoco hará que diga algo que se espera de él, útil para variar.

No puedo escapar de la obligación de sostener que lo dicho desde el sistema europeo de protección se calca para el mecanismo interamericano. En cada trayecto del análisis, en todo el corredor de las órbitas de interés.

Por respeto analítico, iré a los cimientos para la Corte de Costa Rica en la materia. Así, con razón según constatara, se suscribió: “...corresponde dejar claro que cualquiera que haya sido la naturaleza de los actos aludidos, se trata de comportamientos estrictamente prohibidos por el Derecho Internacional de los Derechos Humanos. A ese efecto, la Corte Europea de Derechos Humanos ha señalado, refiriéndose al artículo 3 de la Convención Europea de Derechos Humanos, que el mismo: prohíbe en términos absolutos la tortura y las penas o los tratos inhumanos o degradantes, cualesquiera que sean los actos de la víctima. El artículo 3 no prevé ninguna excepción, en lo cual contrasta con la mayoría de los preceptos de la Convención... y ... no admite derogación ni siquiera en el caso de un peligro público que amenace a la vida de la nación. El mencionado Tribunal ha precisado, en reiteradas ocasiones, que dicha prohibición rige aún en las circunstancias más difíciles para el Estado, tales como las que se configuran bajo la agresión del terrorismo y el crimen organizado a gran escala" ${ }^{114}$. Cabe para la guerra, para estados emergenciales e intervención, suspensión de garantías o ante un clima proprio de inestabilidad política muy continental ${ }^{115}$. La solución es invariable, según se observa.

${ }^{113}$ Cfr. Spataro, Armando (2007), p. 44.

${ }^{114}$ Cfr. CorteIDH, Cantoral Benavides c. Perú, 18/8/00, ap. 95 y nota al 51, con mención de algunos casos aquí recogidos. Desde el ap. 82 este caso abona la expansión o dinámica de los tratos inhumanos a la exposición a una larga incomunicación. También se alude al trauma psicológico.

${ }^{115}$ Cfr. CorteIDH, Baldeón García vs. Perú, 6/4/06, ap. 117. 
Son por igual trasladable a otros campos las reflexiones, como ser lo que rodea a la imposición de una consecuencia jurídica o a la ejecución de la última: "La privación de libertad trae a menudo, como consecuencia ineludible, la afectación del goce de otros derechos humanos además del derecho a la libertad personal. Pueden, por ejemplo, verse restringidos los derechos de privacidad y de intimidad familiar. Esta restricción de derechos, consecuencia de la privación de libertad o efecto colateral de la misma, sin embargo, debe limitarse de manera rigurosa, puesto que toda restricción a un derecho humano sólo es justificable ante el derecho internacional cuando es necesaria en una sociedad democrática. La restricción de otros derechos, por el contrario -como la vida, la integridad personal, la libertad religiosa y el debido proceso- no sólo no tiene justificación fundada en la privación de libertad, sino que también está prohibida por el derecho internacional. Dichos derechos deben ser efectivamente respetados y garantizados como los de cualquier persona no sometida a privación de libertad" ${ }^{116}$. Tanto esto es así que cuando pesa una acusación contra agentes estatales, tras las huellas del intérprete europeo, se presume la responsabilidad más allá de una duda razonable ${ }^{117}$.

Todo lo anterior, más allá de su eficacia, nos deja en que existe una limitación a partir de allí, y no, todo lo contrario, un mandato de intervención, o algo así, para proceder con comportamientos cruzados a la regla, el principio y al valor allí encerrado. En efecto, la prohibición de tortura, tratos crueles, inhumanos o degradantes en el (todo) terreno de lo normativo, parte del reconocimiento y respeto del núcleo de la dignidad humana, de donde se genera por un lado una prudente intervención positiva en virtud de la obligación primaria al respecto, y por el otro una (forzosa o) coherentemente negativa, con igual punto de apoyo. El disparador de disposiciones es la contención de la actuación estatal, no la de su afiebrada soltura. Por esta razón, en mi concepto sencilla desde iure aunque no pueda no serlo de facto, encontrarle fundamento a un acto es, si se permite, una gigantesca contradicción: de lo contrario, carecerían de sentido los delitos-tipos de la Ley 23.097 en Argentina o los recogidos por la Ley 9.455 en Brasil ${ }^{118}$, superadores de otros derechos comparados ${ }^{119}$, en donde acciones positivas o negativas

${ }^{116}$ Cfr.CorteIDH, Instituto de Reeducación del Menor c. Paraguay, 2/9/04, ap. 154 y ss.

${ }^{117}$ Exemplo docit, CorteIDH, Caso de los hermanos Gómez Paquiyauri v. Perú, 8/7/04, ap. 108. Confrontar, ECHR., Aydin v. Turkey, op. cit., ap. 73; Selmouni v. France, op. cit., ap. 88, entre otros de los aquí ut-supra citados.

${ }^{118}$ Incluso refuerzan otras disposiciones, como crime de constrangimento ilegal, art. 146 CPB. Sobre combinaciones por pluralidad de delitos o concurso aparente, BitencourT, Cezar Roberto (2008 b), pp. 359 y ss.

${ }^{119}$ Así lo pienso si en la teoría los confronto con el conjunto de la parte especial del Stgb., según el art. 239a o 239b, 240 ó 343. Algún sector encuentra como piedra de toque, infraconstitucional desde luego, las primeras disposiciones vinculadas a coacción como atentados contra la libertad (que presupone la dignidad), otros los 
vienen definitivamente penadas. Es decisivo comprender que la erradicación de estos hechos cuya comisión en cualquier modalidad es inaceptable, presupone no abrir desde cuanto menos la arquitectura positiva, una puerta trasera para que en la represión no tenga ningún lugar ${ }^{120}$.

Como cuentas pendientes, sin dudas Argentina debe implementar el Protocolo Opcional a la Convención (Brasil ya hizo su parte en 2007) ${ }^{121}$. Su trascendencia internacional supone, como debiera ser, un impacto regional en el proceso de integración: el crecimiento de ambos Estados en lo económico no puede prescindir, sino presuponer un mutuo y constante interés por la defensa y promoción de los derechos fundamentales ${ }^{122}$. A tono con la afirmación, el instrumento prevé la probable visita periódica de un cuerpo especializado -subcomisión de la que se ha impulsado por Naciones Unidas contra tales comportamientos-que resulta ser uno de los más efectivos modos de prevenir e impedir la tortura o los tratos crueles, inhumanos y degradantes: los reportes del Comité son usualmente empleados por la jurisprudencia europea frente a denuncias en la materia. Autoridades nacionales, con obligación primaria en el tema -entre los que sobresalen jueces de ejecución, que debieran tener y a la vez concurrir a un despacho oficial en cada penitenciaria ${ }^{123}$, y magistrados todos (también el Ministerio Público Fiscal) que tienen todavía a su cargo una obligación docente con las fuezas auxiliares del

últimos ligados a la actuación estatal en conexión con investigación o proceso judicial. Ampliar, WiLHELM, Jens Philipp, Folter -verboten, erlaubt oder gar geboten-" (presentación en Mannheimer Praxisseminars im Strafrecht"), Universität Mannheim, 1/7/03 (consultado en noviembre 1 de 2009) (http://jwilhelm.de/ foltmat.pdf); y coincidente con mi desarrollo, MaIHOLd, Harald, Folterknechte im Dienste des Rechtsstaats? Die "Präventivfolter" vor dem Forum des Strafrechts", Humbolt Forum Recht, HFR 11/2004. Por ejemplo un reciente Kommentar no contiene un supuesto de tortura como hipótesis típica, cfr. LACKNER, Karl-KüHL, Kristian (2007), pp. 1025, 1029 y ss.; y p. 1491.

${ }^{120}$ Puede ser que para un sujeto pasivo sea indistinto el sujeto activo que lo atormente. Sin embargo es preciso, principalmente desde lo que toca a Brasil, distinguir que la tortura es en especial una desviación en la relación Estado-individuo y aunque ataca la dignidad, también resulta un delito contra el sentido y definición del primero, en términos democráticos, según la jurisprudencia de la Corte Europea. No es ni basta asociarla con un crimen contra la administración pública. En contra, MuÑoz Conde, Francisco (2004), p. 183.

${ }^{121}$ Asamblea General de Naciones Unidas adoptó un Protocolo Adicional a la Convención en diciembre 18 de 2002, sujeto a firma y ratificación a partir de febrero 4 de 2003. Mientras Argentina estudia la implementación, lo cierto es que todavía el esfuerzo de Brasil no se ve traducido en resultados que se puedan valorar como positivos en todas las áreas y especial en lo que hace a detención policial y ejecución penal.

${ }^{122}$ Cfr. Machado Pelloni, Fernando M. (2009), pp. 15 y ss.

${ }^{123}$ Lo que ocurre con los agentes penitenciarios o bien no se puede decir porque los internos temen represalias o bien porque hay una enorme dificultad probatoria, a partir justamente de la distancia entre las sedes judiciales y el espacio geográfico donde la tortura, los tratos crueles, inhumanos o degradantes tienen su lugar, agravado por la transpersonalidad de los hechos: cuando no son contra los detenidos, se extienden a sus propias familias cuando los visitan. 
sistema judicial-124 y el sueño de un Tribunal de Derechos Fundamentales del Mercosur -que no competirá con la Corte de San José, sino que debe trabajar en conjunto, habida cuenta de la extensión del subcontinente e identificación con valor agregado de un grupo de países- son coordenadas estrictas de un rumbo que no se debiera perder, bajo ningún pretexto argumental.

No obstante los problemas a resolver en lo inmediato apuntan a no caer en la rendición del nuevo suplicio, el que existe y al que se renuncia a tratar el Estado democrático, que por escrito y oralmente lo niega, sea que lo oculte, lo transforme o lo minimalice. En la historia, paradojalmente el poder se jactaba de su ceremonia. Como lo veo, ahora lo hace pero con su depravada indiferencia tanto para los autores materiales como para con sus víctimas: los casos de violaciones a la regla, en definitiva, apenas prueban eso que indica, (casi) siempre, que se podían haber evitado. Nada que se diga podrá cambiarlo.

Lo más serio -sobre lo cual el debate no se ha dado con solidez- es que a largo plazo el Estado democrático hipoteca su credibilidad y su superioridad valorativa $^{125}$.

\section{BiBLIOGRAFÍA}

Agamben, Giorgio (2005): Lo que queda de Auschwitz (Ciò che resta di Auschwitz, trad. Gimeno Cuspinera, A., Valencia, Pre-Textos).

Alexy, Robert (2002): Teoría de los Derechos Fundamentales (Theorie der Grundrechte, trad. Garzón Valdés, E., Madrid, Centro de Estudios Políticos y Constitucionales).

Amengual Coll, Gabriel (2001): La moral como derecho, (Madrid, Trotta).

Antolisei, Francesco (2000): Manuale di Diritto Penale. Parte Generale, (Milano, Giuffrè).

Bentham, Jeremy (1973): “On torture”, en AA.VV., Bentham on Torture, (Twining, William, Northern Ireland Legal Quaterly, 24-3).

Bitencourt, Cezar R. (2008): Tratado di Direito Penal. Parte Geral. 1, (Sao Paulo, Saravia).

Bitencourt, Cezar Roberto (2008 b): Tratado de Direito Penal. Parte Especial 2, (Sao Paulo, Saravia).

${ }^{124}$ Tiene razón la sentencia, al abordar el art. 174 CPE., afín a nuestras leyes: "El problema de la tortura no es, desde luego, ni siquiera primordialmente, un problema de leyes, sino de sensibilidad y de formación de las personas encargadas de aplicar esas leyes”. Cfr. Muñoz Conde, Francisco (2004), p. 192.

${ }^{125}$ Cfr. Hassemer, Winfried (2007), p. 145. 
Bobbio, Norberto (1992): Teoría General del Derecho (trad. Rozo Acuña, E., Madrid, Debate).

BONANATE, Luigi (2004): La política internazionale fra terrorismo e guerra, (BariRoma, Laterza).

Bowring, Bill (2008): The degradation of the International Legal Order? The Rehabilitation of Law and the Possibility of Politics, (London, RoutledgeCavendish).

CARrio, Genaro (1973): Los límites del lenguaje normativo, (BsAs., Astrea).

CASSESE, Antonio (2008): I dirittti umani oggi, (Laterza, Roma-Bari).

DwORKIN, Ronald (1985): A matter of principle (Cambridge, Harvard University Press).

Dworkin, Ronald (1986): Law's empire, (Cambridge, Belknap-Harvard University Press).

EkmeKdJIÁn, Miguel A. (1993): Tratado de Derecho Constitucional, T.1, (Buenos Aires, Depalma).

Fiandaca, G.-Musco, E. (2001): Diritto Penale. Parte Generale, (Bologna, Zanichelli).

FouCAult, Michel (2008): Vigilar y castigar (Surveiller et punir, trad. Garzón del Camino, A., Bs.As., Siglo XXI).

García Figueroa, Alfonso (1998): Principios y positivismo jurídico, (Madrid, Centro de Estudios Políticos y Constitucionales).

Gössel, Karl Heinz (2007): “¿Contiene el derecho alemán prohibiciones “absolutas" de tortura, que rigen sin excepción?" (trad. Styma, Dirk), en AAVV. Revista de Derecho Procesal Penal, Donna, E. (director), 2007-1 (Santa Fe, Rubinzal-Culzoni).

Gracia Martín, L.-Boldova Pasamar, M.A.-Alastuey Bodón, C. (2000): Tratado de las consecuencias jurídicas del delito, (Gracia MARTín, L. Coordinador, Valencia, Tirant lo Blanch).

Harris, D. J.-O'Boyle, M.-Bates, E. P.-Buckley, C.M. (2009): Law of the European Convention on Human Rights, (NYC, Harris, O'Boyle \& Warbrick, Oxford University Press).

Hart, H. L. A. (1997): The Concept of Law (with the Postscript edited by Penelope Bulloch \& Joseph Raz, Oxford Clarendon).

Hassemer, Winfried (2007): Direito Penal libertario (Freiheitliches Strafrecht, trad. Greve, Regina, Belo Horizonte, Del Rey).

HeInZ, Karl (2007): “¿Contiene el derecho alemán prohibiciones “absolutas” de tortura, que rigen sin excepción?” (trad. Styma, Dirk), en AAVV. Revista de 
Derecho Procesal Penal, Donna, E. (director), 2007-1 (Santa Fe, RubinzalCulzoni).

Jakoвs, Gunther (1997): Derecho Penal. Parte General, (Strafrecht. Allgemeiner Teil, trad. Cuello Contreras, J.-Serrano González de Murillo, J.L., Madrid, Marcial Pons).

KanT, Immanuel (1999): Grundlegung zur Metaphysik der Sitten, (Hamburg, Felix Meiner Verlag).

Kaufmann, Arthur (1976): Das Schuldprinzip. Eine strafrechtlich-rechphilosophische Untersuchung (Heidelberg, Carl Winter universitätverlag).

LaCKNER, Karl-KüHL, Kristian (2007): Strafgesetzbuch Kommentar, (München, C.H. Beck).

Machado Pelloni, Fernando M. (2008): "Derechos Fundamentales e Interpretación”, en Revista da Faculdade de Direito UniRitter No 9, (Porto Alegre-Rio Grande do Sul, UniRitter dos Reis).

Machado Pelloni, Fernando M. (2009): "Derecho Penal Económico: su legitimación para la defensa de Derechos Fundamentales", Revista de Estudos Criminais $N^{\circ} 32$, (Porto Alegre, Notadez).

Machado Pelloni, Fernando M., Desobediencia \& delito, tesis doctoral, inédita.

Mainold, Harald, Folterknechte im Dienste des Rechtsstaats? Die "Präventivfolter" vor dem Forum des Strafrechts", Humbolt Forum Recht, HFR 11/2004.

Mantovani, Ferrando (1984): Il problema della criminalità, (Padova, Cedam).

Moraes, Alexandre De (2007): Dereitos Humanos Fundamentais, (Sao Paulo, Atlas).

Muñoz Conde, Francisco (2004): Derecho Penal. Parte Especial, (Valencia, Tirant lo Blanch.

Piovesan, Flávia-Stanziola Vieira, Renato (2009): "A Forca normativa dos princípios constitucionais fundamentais: a dignidade da pessoa humana", en PIOVESAN, Flávia, "Temas de Direitos Humanos", (Sao Paulo, Saravia).

Raz, Joseph (1997), The Authority of Law, (Oxford, Clarendon).

Roxin, Claus (1997): Derecho Penal. Parte General (Strafrecht Allgemeiner Teil, trad. Luzon Peña, D.M.-Díaz y García Conlledo, M.-de Vicente Remesal, J., Madrid, Civitas).

SCHMIDHÄUSER, Eberhard (1972): Einführung in das Strafrecht, (Hamburg, Rowohlt).

SATZger, Helmut (2005): Internationales und Europäisches Strafrecht, (BadenBaden, Nomos). 
SPATARO, Armando (2007): Terrorismo e crimine transnazionale: aspetti giuridici e premesse socio organizzative del fenomeno, (Roma, Consiglio Superiore della Magistratura).

Zagrebelsky, Gustavo (1992): Il diritto mite, (Torino, Einaudi).

\section{Jurisprudencia de la Corte Europea de Derechos Humanos}

Los fallos que se citan han sido extraídos de la base disponible on line, www. echr.coe.int/ en case law, HUDOC database. Se incluye la demanda (app.) para mejor referencia.

Aktas v. Turkey (judgment), app. 24.351/94, rta. 24/04/2003

Aydin v. Turkey, app. 57/1996/676/866, rta. 25/9/97

Gülec v. Turkey, app. 21593/93, rta. 27/7/98

Ireland v. United Kingdom, app. 5310/71, rta. 18/1/78

Jabari v. Turkey, app. 40035/98, rta. 11/7/00

Kafkaris v. Cyprus, app. 21906/04, rta. 12/2/08

Kaya v. Turkey (judgment), app. 22729/93, rta. 19/2/1998

Lithgow and others $v$. United Kingdom, app. 9006/80;9262/81; 9263/81; 9265/81;

9266/81; 9313/81; 9405/81, rta. 8/7/1986

Mayzit v. Russia, app. 63378/00, rta. 20/1/05

Novoselov v. Russia, app. 66460/01, rta. 2/9/05

Peers v. Greece, app. 28524/95, rta.19/4/01

Ribitsch v. Austria, app. 18896/91, rta. 4/12/95

Said v. Netherlands, app. 2345/02, rta. 5/10/05

Selmouni v. France, app. 25803/94, rta. 26/7/99

Soering $v$. The United Kigndom, app. 14038/88, rta. 7/7/89

Tomasi v. France, app. 12850/87, rta. 27/8/92

Tyrer v. United Kingdom, app. 5856/72, rta. 25/4/78

Z. v. Finland, app. 22009/93, rta. 25/02/1997 